\title{
Guillain-Barré syndrome following varicella-zoster virus infection
}

\author{
Badrul Islam ${ }^{1,2} \cdot$ Zhahirul Islam $^{1}$ • Corine H. GeurtsvanKessel ${ }^{3}$ • Israt Jahan ${ }^{1}$ • Hubert P. Endtz ${ }^{1,2,4}$. \\ Quazi D. Mohammad ${ }^{5} \cdot$ Bart C. Jacobs $^{6}$
}

Received: 17 January 2018 / Accepted: 20 January 2018 / Published online: 6 February 2018

(C) Springer-Verlag GmbH Germany, part of Springer Nature 2018

\begin{abstract}
We describe the frequency, clinical features, and electrophysiological and immunological phenotypes of Guillain-Barré Syndrome (GBS) patients treated at a single institution in Bangladesh who had preceding chicken pox (primary Varicellazoster virus [VZV] infection) within 4 weeks of GBS onset. A literature review of GBS cases preceding VZV infection is also provided. Diagnosis of GBS was based on the National Institute of Neurological Disorders and Stroke criteria for GBS. Serum anti-VZV IgM and IgG antibodies were quantified by indirect chemiluminescence immunoassay (CLIA); anti-Campylobacter jejuni IgG, IgM, and IgA antibodies and anti-ganglioside GM1 IgM and IgG antibodies, by enzyme-linked immunosorbent assays. Neurophysiologic subtypes were categorized following the Hadden criteria. Of 536 patients with GBS, 7 (1.3\%) had chicken pox within 4 weeks before GBS onset. Four of the seven cases were male (age range, 23 to 40 years old). All seven patients were bed-bound, six had sensory symptoms, and three required mechanical ventilation for respiratory failure. All seven patients had CSF albuminocytologic dissociation and evidence of demyelination in nerve conduction studies. Anti-VZV IgM antibodies were present and anti-GM1 and anti-Campylobacter jejuni lipo-oligosaccharides (LOS) were negative in all cases. All patients had excellent outcome at 1 year (able to run). A systematic literature review of GBS cases related to VZV revealed 39 previously reported patients with comparable clinical presentations and outcomes, of which 36 had neurophysiologic evidence of demyelination. VZV infection is associated with the demyelinating subtype of GBS, clearly distinct from the axonal form of GBS that predominate in countries like Bangladesh.
\end{abstract}

Keywords Varicella zoster virus · Chicken pox $\cdot$ Shingles $\cdot$ Herpes zoster $\cdot$ Guillain-Barré syndrome

Electronic supplementary material The online version of this article (https://doi.org/10.1007/s10096-018-3199-5) contains supplementary material, which is available to authorized users.

Badrul Islam

badrul.islam@icddrb.org; bislamdmch@gmail.com

1 Laboratory Sciences and Services Division (LSSD), International Centre for Diarrheal Diseases Research (icddr,b), Dhaka, Bangladesh

2 Department of Medical Microbiology and Infectious Diseases, Erasmus MC, University Medical Center Rotterdam, Rotterdam, The Netherlands

3 Department of Viroscience, Erasmus MC, University Medical Center Rotterdam, Rotterdam, The Netherlands

4 Fondation Mérieux, Lyon, France

5 National Institute of Neuroscience \& Hospital, Dhaka, Bangladesh

6 Departments of Neurology and Immunology, Erasmus MC, University Medical Center Rotterdam, Rotterdam, The Netherlands

\section{Introduction}

Preceding infections are the predominant trigger of GuillainBarré Syndrome (GBS) [1]. Current evidence suggests specific antecedent infections can influence the clinical phenotype, course, and outcome of GBS. Among the GBS-related pathogens that have been extensively studied, Campylobacter jejuni is associated with acute motor axonal neuropathy (AMAN) presenting with severe weakness and poor outcome $[2,3]$. Similarly, cytomegalovirus infections are associated with sensory-motor acute inflammatory demyelinating polyneuropathy (AIDP) [4]. Epstein-Barr virus, hepatitis E virus, Mycoplasma pneumonia, varicella-zoster virus (VZV), and Zika virus have also been related to GBS, though the associated clinical and electrophysiological variants are less well-defined $[1,5,6]$. The type of preceding infection may also influence the differences in the frequency of GBS variants observed between geographical regions. In Bangladesh, the frequency of preceding $C$. jejuni infections is around 50\% [3], which may explain the exceptionally high 
frequency of AMAN compared to other regions. Other Asian and South American countries have also reported higher frequencies of AMAN [2, 7-9] compared to Europe and North American countries, where AIDP is the predominant variant $[10,11]$. Other than $C$. jejuni, the preceding infections in patients with GBS from Bangladesh are not well-defined. Infection with VZV has been reported as a rare preceding event in GBS, mainly described in case reports. One population-based study revealed an increased risk of GBS following herpes zoster attack, though information on clinical and neurophysiologic subtype(s) was lacking [12]. Here, we report the frequency of preceding chickenpox or varicella infection in a cohort of 536 consecutive patients with GBS from Bangladesh and provide detailed analyses of the associated clinical and electrophysiological features. An overview of 39 previously reported VZV-related GBS cases [13-42] is also provided, and probable pathogenesis are discussed.

\section{Methods}

\section{Patients}

Between March 2010 and June 2016, 536 patients with GBS of all ages presenting within 2 weeks of the onset of weakness at Dhaka Medical College Hospital (DMCH) have been prospectively enrolled. Diagnosis of GBS was as per the National Institute of Neurological Disorders and Stroke criteria for GBS [43]. Patients with GBS having clinical features of primary VZV (chicken pox) infection within 4 weeks of the onset of weakness were included in this study. Data were collected regarding clinical presentation, specifically severity of weakness (GBS disability score and MRC sum score), sensory disturbance, cranial nerve dysfunction, dysautonomia, CSF analysis, and nerve conduction study results. Patients were followed up at fixed intervals for 1 year to observe neurological outcome. All the patients provided informed written consent and the study was approved by the ethical bodies of the International Centre for Diarrhoeal Disease Research, Bangladesh (icddr,b) and DMCH.

\section{Immunological assays}

Serum anti-VZV IgM and $\operatorname{IgG}$ antibodies were quantified using indirect chemiluminescence immunoassay (CLIA) on DiaSorin-LIAISON® XL (DiaSorin S.p.A, Vercelli, Italy) at the Department of Viroscience, Erasmus MC, Rotterdam. The cutoff for IgM positivity was $1.1 \mathrm{~S} / \mathrm{CO}$; values between 0.9 $1.1 \mathrm{~S} / \mathrm{CO}$ were interpreted as equivocal following the manufacturer's instructions. Anti-C. jejuni IgG antibodies were measured using an indirect enzyme-linked immunosorbent assay (ELISA); anti-C. jejuni IgM and IgA antibodies, by antibody class capture ELISAs based on previously described positivity criteria [44]. Serum anti-GM1 IgG antibodies and antibody reactivity to $C$. jejuni LOS were assessed using ELISAs at the icddr,b. Patients were considered positive for anti-GM1 IgG antibodies if the optical density was $>0.2$ [3]. Serum antibodies against LOS were quantified using an ELISA as described previously [45] with some modifications [46]. Serum was considered anti-LOS positive if the corrected OD was greater than the mean plus three times standard deviation (SD) value of control samples.

\section{Nerve conduction studies}

Nerve conduction studies (NCS) were performed on one side of the body according to standardized and strict protocols using a Viking Select EMG system (CareFusion, San Diego, CA, USA). Neurophysiologic subtypes of GBS were categorized as per the Hadden criteria [7].

\section{Literature review}

A systematic literature review was conducted using PubMed/ MEDLINE and EBSCO. No timeframe was selected; search terms were "Guillain-Barre syndrome," "chickenpox," "varicella," "shingles," and "herpes zoster."

\section{Statistical analysis}

Categorical data are presented as numbers, percentages, and proportions; numerical data, as medians and interquartile ranges (IQRs). Differences in proportions were examined using Fisher's exact test and median values using the Wilcoxon-Mann-Whitney $U$ test with SPSS 22 software (IBM SPSS Statistics for Windows Version 22.0; IBM Corp., Armonk, NY, USA). $P$ values are two-sided; $P<0.005$ after Bonferroni correction was considered significant.

\section{Results}

\section{Patients and clinical features}

Seven out of $536(1.3 \%)$ patients with GBS had fever and generalized vesicular skin eruption characteristic of chicken pox or varicella, within 4 weeks before the onset of weakness. Demographic and clinical features, CSF and NCS subtypes, serological and immunological findings, and outcomes are summarized in Table 1. Four of the seven cases were male; age ranged from 23 to 40 years old. Primary VZV skin eruption within 2 weeks of the onset of weakness was present in five patients and within 4 weeks in two patients. Six of the seven patients had the sensory-motor subtype of GBS; all were bed-bound with MRC sum scores ranging from 8 to 
Table 1 Clinical features of GBS associated with varicella-zoster virus $(\mathrm{VZV})$ infection

\begin{tabular}{|c|c|c|c|}
\hline \multirow[t]{2}{*}{ Characteristic } & \multicolumn{2}{|c|}{ Post-chicken pox GBS } & \multirow{2}{*}{$\begin{array}{l}\text { Post-shingles GBS } \\
\text { Reported cases } \\
(n=15)^{\mathrm{a}}\end{array}$} \\
\hline & $\begin{array}{l}\text { Bangladesh } \\
(n=7)\end{array}$ & $\begin{array}{l}\text { Reported cases } \\
(n=24)^{\mathrm{a}}\end{array}$ & \\
\hline Age, years (median, IQR) & $34(29-38)$ & $32(9-42)$ & $66(57-74)^{\mathrm{b}}$ \\
\hline Male/female ratio & $4 / 3$ & $17 / 7$ & $10 / 5$ \\
\hline $\begin{array}{l}\text { VZV skin lesions to weakness, days } \\
\text { (median, IQR) }\end{array}$ & $11(10-18)$ & $8(7-13)$ & $10(8-28)$ \\
\hline \multicolumn{4}{|l|}{ Clinical type } \\
\hline Sensory-motor & $6 / 7(86 \%)$ & $13 / 24(54 \%)$ & $14 / 15(93 \%)$ \\
\hline Pure motor & $1 / 7(14 \%)$ & $11 / 24(46 \%)$ & $1 / 15(7 \%)$ \\
\hline \multicolumn{4}{|l|}{ Severity of weakness } \\
\hline Tetraparesis & 7/7 (100\%) & $20 / 24(83 \%)$ & $15 / 15(100 \%)$ \\
\hline Paraparesis & $0 / 7(0 \%)$ & $4 / 24(17 \%)$ & $0 / 15(0 \%)$ \\
\hline \multicolumn{4}{|l|}{ Deep tendon reflex } \\
\hline Hypo/absent & $7 / 7(100 \%)$ & $23 / 24(96 \%)$ & $15 / 15(100 \%)$ \\
\hline Intact & $0 / 7(0 \%)$ & $1 / 24(4 \%)$ & $0 / 15(0 \%)$ \\
\hline \multicolumn{4}{|l|}{ Cranial nerve paresis } \\
\hline Facial & $5 / 7(71 \%)$ & $13 / 24(54 \%)$ & $7 / 15(47 \%)$ \\
\hline Bulbar & $6 / 7(86 \%)$ & $4 / 24(17 \%)$ & $2 / 15(13 \%)$ \\
\hline Extra-ocular & $1 / 7(14 \%)$ & $0 / 24(0 \%)$ & $2 / 15(13 \%)$ \\
\hline Mechanical ventilation & $3 / 7(43 \%)$ & $4 / 24(17 \%)$ & $2 / 15(13 \%)$ \\
\hline Autonomic dysfunction & $2 / 7(29 \%)$ & $3 / 24(13 \%)$ & $2 / 15(13 \%)$ \\
\hline CSF protein, mg/dL (median, IQR) & $360(270-780)$ & $114(77-105)$ & $100(59-139)$ \\
\hline CSF cells, n/mL (median, IQR) & $0(0-0)$ & $1(0-12)$ & $3(2-6)$ \\
\hline $\mathrm{CSF}, \mathrm{ACD}$ & $7 / 7(100 \%)$ & $19 / 22(86 \%)$ & $11 / 14(79 \%)$ \\
\hline \multicolumn{4}{|l|}{ NCS type } \\
\hline AIDP & $7 / 7(100 \%)$ & $21 / 24(88 \%)$ & $15 / 15(100 \%)$ \\
\hline Axonal & $0 / 7(0 \%)$ & $3 / 24(13 \%)$ & $0 / 15(0 \%)$ \\
\hline \multicolumn{4}{|l|}{ Antecedent infection, positive/tested (\%) } \\
\hline VZV & $7 / 7(100 \%)$ & $6 / 6(100 \%)$ & $6 / 6(100 \%)$ \\
\hline C. jejuni & $1 / 7(14 \%)$ & $0 / 0$ & $0 / 0$ \\
\hline Other infections & $0 / 7(0 \%)$ & $0 / 0$ & $0 / 1(0 \%)$ \\
\hline \multicolumn{4}{|l|}{ Autoantibodies, positive/tested (\%) } \\
\hline Anti-GM1 antibodies & $0 / 7(0 \%)$ & $1 / 2(50 \%)$ & $1 / 2$ \\
\hline Specific autoantibodies & $0 / 0$ & $0 / 1(0 \%)$ & $1 / 4(25 \%)$ \\
\hline \multicolumn{4}{|l|}{ Treatment } \\
\hline IVIG/PE & $0 / 7(0 \%)$ & $14 / 23(61 \%)$ & $6 / 15(40 \%)$ \\
\hline Steroids & $0 / 7(0 \%)$ & $0 / 23(0 \%)$ & $3 / 15(20 \%)$ \\
\hline Supportive care & $7 / 7(100 \%)$ & $9 / 23(39 \%)$ & $6 / 15(40 \%)$ \\
\hline \multicolumn{4}{|l|}{ GBS disability score $^{\mathrm{c}}$ at 1 year } \\
\hline 0 or 1 & $4 / 7(57 \%)$ & $16 / 22(73 \%)$ & $9 / 14(64 \%)$ \\
\hline 2 & $3 / 7(43 \%)$ & $6 / 22(27 \%)$ & $3 / 14(21 \%)$ \\
\hline 6 & $0 / 7(0 \%)$ & $0 / 22(0 \%)$ & $2 / 14(14 \%)$ \\
\hline
\end{tabular}

$A C D$ albuminocytologic dissociation

${ }^{\text {a }}$ Patient information is available in Supplementary Table 2

${ }^{\mathrm{b}}$ Reported patients with post-shingles GBS were significantly older than our cohort and the reported post-chicken pox GBS cohort $(P<0.0001)$

${ }^{\mathrm{c}}$ GBS disability score: 2 = able to walk 10 m unassisted but unable to run; $3=$ able to walk $10 \mathrm{~m}$ with help; $4=$ bedridden or chair bound; $5=$ requiring assisted ventilation; $6=$ died 
42. Sensory abnormalities were strictly restricted to the distal extremities in a stock and gloving distribution. Sensation was impaired in six patients (impaired position sense in five patients; both impaired touch and position sense in one patient). Cranial nerve involvement was present in six patients (facial and bulbar cranial nerve dysfunction in five patients; extraocular cranial nerve dysfunction in one patient; bulbar cranial nerve dysfunction only in one patient; cranial nerves not involved in one patient). Two patients experienced autonomic dysfunction (both had hypertension and tachycardia) during the first 2 months after the onset of weakness. Three patients required mechanical ventilation (for 4,30 , and 45 days, respectively). CSF was examined in all seven patients; the timepoint of the CSF tap ranged from 8 to 25 days after the onset of weakness. All patients exhibited albuminocytologic dissociation in CSF (Table 1). All patients received supportive care; none were treated with intravenous immunoglobulin or plasma exchange.

\section{Nerve electrophysiology}

All seven patients underwent NCS; the time-point of NCS ranged from 13 to 25 days after the onset of weakness. All cases were neurophysiologically classified as demyelinating GBS based on slowing of the motor nerves. NCS values are summarized in Table 2. Prolonged distal latency in at least two motor nerves was detected in all patients. Decreased motor conduction velocity in at least two nerves was detected in two patients. In-excitable distal sensory nerve action potential (SNAP) in at least two individual nerves was found in six patients; SNAPs were low in the other patient. Sural SNAP was preserved (sural sparing pattern) in five cases.

\section{Serology}

Anti-VZV IgM antibodies were detected in all seven patients (results were equivocal in two patients), and all patients were also anti-VZV IgG-positive. Antibodies against $C$. jejuni were not present in six cases; one patient had IgM antibodies against $C$. jejuni. Antibodies against the ganglioside GM1 and $C$. jejuni LOS were not detected in any cases. Furthermore, anti-VZV IgM antibodies were not detected in a random selection of 19 patients with GBS who did not develop cutaneous lesions in the 4 weeks preceding the onset of weakness.

\section{Outcome}

Three patients were able to walk independently at 1 month, and all seven patients could walk independently at 3 months after the onset of weakness. Sensory dysfunction subsided within 3 months in five of the six affected patients. Cranial nerve dysfunction recovered within 4 months in five patients.
At 1 year, four patients were completely cured and three patients were able to run but had minor residual disabilities (paresthesia over the distal feet in one patient, unilateral facial weakness in one patient, residual fatigue in one patient).

\section{Literature review}

Combined searches using the Boolean logic operators "AND" and "OR" identified 102 citations in PubMed and 79 citations in EBSCO. Of the 105 unique results, 60 did not explore the association between VZV and GBS, 10 were not in English, and 5 described patients with VZV-related GBS but did not mention the neurophysiological subtype; 30 articles were included in the literature review. The demographic and clinical features, neurophysiological subtypes, and serology for the 39 patients who developed GBS after VZV (primary VZV/ chicken pox, 24 cases; herpes zoster, 15 cases) reported in these 30 articles are summarized in Table 1; the details of individual patients are illustrated in Supplementary Tables 1 and 2.

\section{GBS following chicken pox or varicella}

Of the 24 reported patients [13-32] who developed GBS after chicken pox (Table 1), 17 (71\%) were male (age range, 2 to 53 years old). Duration between skin rash and developing weakness ranged from 4 to 21 days. Most patients were quadriplegic $(83 \%)$ and had sensory symptoms $(57 \%)$ and cranial nerve dysfunction $(62 \%)$. CSF albuminocytologic dissociation was noted in $86 \%(19 / 22)$ patients. Twenty-one $(88 \%)$ patients had evidence of the demyelinating form of GBS. At 1 year, 22 patients could walk independently; outcome was not reported for two patients. Evidence of recent VZV infection in serum was present in all eight patients who were screened for VZV. PCR to detect VZV in CSF was performed for five patients; one patient was positive. Screening of other infectious agents related to GBS was not performed for any patient. Two patients were screened for anti-ganglioside antibodies; anti-GM1 and anti-GD1b IgM were detected in one patient. One patient was screened and negative for specific autoantibodies to self-antigens. Lymphocyte subsets were examined in one patient; a marked decrease in suppressor T cells and slight decrease in helper T cells with an inverted helper/ suppressor $\mathrm{T}$ cell ratio was observed.

\section{GBS following herpes zoster or shingles}

Among the 15 reported patients [29, 30, 33-42] who developed GBS after herpes zoster (Table 1), 10 (67\%) were male (age range, 42 to 77 years old). Duration between skin rash and developing weakness was 3 to 42 days. All 15 patients were quadriplegic, had sensory symptoms, and most had cranial nerve dysfunction (71\%). CSF albuminocytologic dissociation was noted in $77 \%(10 / 13)$ patients. All 15 cases were 
Table 2 Nerve conduction study data for the seven patients with GBS following chicken pox

\begin{tabular}{|c|c|c|c|c|c|c|c|}
\hline & \multicolumn{7}{|c|}{ Patient number } \\
\hline & 1 & 2 & 3 & 4 & 5 & 6 & 7 \\
\hline Days from onset of weakness to NCS & 18 & 20 & 14 & 13 & 25 & 14 & 18 \\
\hline \multicolumn{8}{|l|}{ Motor NCS } \\
\hline \multicolumn{8}{|l|}{ Median } \\
\hline dCMAP ${ }^{a}$ & 7.2 & 4.4 & 3.7 & 3.7 & 5.9 & 1.2 & 2.4 \\
\hline $\mathrm{DML}^{\mathrm{b}}$ & 5.1 & 7.0 & 9.1 & 9.0 & 6.7 & 10 & 7.0 \\
\hline $\mathrm{MCV}^{\mathrm{c}}$ & 37 & 33 & 50 & 38 & 50 & 50 & 62 \\
\hline \multicolumn{8}{|l|}{ Ulnar } \\
\hline dCMAP & 7.6 & 3.6 & 3.8 & 4.0 & 6.8 & 2.7 & 2.8 \\
\hline DML & 3.8 & 6.0 & 7.0 & 5.1 & 4.6 & 5.7 & 5.7 \\
\hline $\mathrm{MCV}$ & 40 & 37 & 58 & 43 & 51 & 51 & 56 \\
\hline \multicolumn{8}{|l|}{ Peroneal } \\
\hline dCMAP & 1.5 & 1.0 & 1.7 & 1.3 & 13 & 1.8 & 1.7 \\
\hline DML & 7.6 & 8.4 & 9.1 & 6.5 & 70 & 8.9 & 7.5 \\
\hline $\mathrm{MCV}$ & 35 & 30 & 36 & 43 & 43 & 43 & 46 \\
\hline \multicolumn{8}{|l|}{ Tibial } \\
\hline dCMAP & 1.0 & 1.5 & 3.6 & 0.9 & 3.5 & 4.3 & 1.5 \\
\hline DML & 8.3 & 8.4 & 5.8 & 10 & 6.4 & 7.7 & 4.8 \\
\hline $\mathrm{MCV}$ & 37 & 39 & 31 & NA & 42 & 40 & 38 \\
\hline \multicolumn{8}{|l|}{ Sensory NCS } \\
\hline \multicolumn{8}{|l|}{ Median } \\
\hline dSNAP ${ }^{\mathrm{d}}$ & 7 & NR & NR & NR & NR & NR & NR \\
\hline $\mathrm{DSL}^{\mathrm{e}}$ & 3.1 & NR & NR & NR & NR & NR & NR \\
\hline $\mathrm{SCV}^{\mathrm{f}}$ & 41 & NR & NR & NR & NR & NR & NR \\
\hline \multicolumn{8}{|l|}{ Ulnar } \\
\hline dSNAP & 7 & NR & NR & NR & NR & 17 & NR \\
\hline DSL & 2.7 & NR & NR & NR & NR & 2.8 & NR \\
\hline $\mathrm{SCV}$ & 45 & NR & NR & NR & NR & 50 & NR \\
\hline \multicolumn{8}{|l|}{ Sural } \\
\hline dSNAP & 10 & NR & 12 & 19.5 & 10 & NR & 11 \\
\hline DSL & 2.4 & NR & 2.3 & 1.8 & 3.0 & NR & 3.4 \\
\hline SCV & 42 & NR & 52 & 50 & 47 & NR & 35 \\
\hline
\end{tabular}

dCMAP distal compound muscle action potential, $D M L$ distal motor latency, $M C V$ motor conduction velocity, $d S N A P$ distal sensory nerve action potential, $D S L$ distal sensory latency, $S C V$ sensory conduction velocity, $N R$ non-recordable

${ }^{\mathrm{a}}$ Lower limit of normal (LLN) for dCMAP amplitude: median nerve, $4.5 \mathrm{mV}$; ulnar nerve, $7.9 \mathrm{mV}$; peroneal nerve, $2 \mathrm{mV}$; tibial nerve, $5 \mathrm{mV}$

${ }^{\mathrm{b}}$ Upper limit of normal (ULN) for DML: median nerve, $4.5 \mathrm{~ms}$; ulnar nerve, $3.7 \mathrm{~ms}$; peroneal nerve; $6.5 \mathrm{~ms}$; tibial nerve, $6.0 \mathrm{~ms}$

${ }^{\mathrm{c}}$ LLN for motor CV: median nerve, $50 \mathrm{~m} / \mathrm{s}$; ulnar nerve, $50 \mathrm{~m} / \mathrm{s}$; peroneal nerve, $40 \mathrm{~m} / \mathrm{s}$; tibial nerve, $40 \mathrm{~m} / \mathrm{s}$

${ }^{\mathrm{d}} \mathrm{LLN}$ for dSNAP amplitude: median nerve, $10 \mu \mathrm{V}$; ulnar nerve, $6 \mu \mathrm{V}$; sural nerve, $4 \mu \mathrm{V}$

${ }^{\mathrm{e}} \mathrm{ULN}$ for DSL: median nerve, $3.2 \mathrm{~ms}$; ulnar nerve, $3.1 \mathrm{~ms}$; sural nerve, $3.6 \mathrm{~ms}$

${ }^{\mathrm{f}} \mathrm{LLN}$ for SCV: median nerve, $50 \mathrm{~m} / \mathrm{s}$; ulnar nerve, $50 \mathrm{~m} / \mathrm{s}$; sural nerve, $40 \mathrm{~m} / \mathrm{s}$ reported to have the demyelinating form of GBS. Nine patients were reported to have a good clinical recovery, one patient had residual motor weakness at 6 months, one patient was bed-bound at 1 month (last follow-up), one patient was not followed up and two patients died. Anti-VZV antibodies were investigated in seven patients: anti-VZV IgM was detected in both serum and CSF in three patients, in serum in three patients, and in CSF in one patient. PCR was performed for VZV in CSF in three patients; all were negative. Screening for infectious agents related to GBS other than VZV was 
performed for one patient and yielded negative results. Antiganglioside antibodies were not assessed in any patients. Specific autoantibodies to self-antigens were screened-and were absent-in one patient. Lymphocyte subsets were examined in two patients; one had an abnormal helper/suppressor T cell ratio and the other (known HIV-positive) had decreased CD4 T cells with a decreased CD4/CD8 T cell ratio.

\section{Discussion}

In Bangladesh, GBS associated with chicken pox or primary VZV infection has characteristic sensory-motor neurologic involvement, a demyelinating pattern on nerve electrophysiology, and favorable clinical outcome. This is remarkable, considering that the majority of Bangladeshi patients with GBS have the axonal form of GBS. Although muscle weakness at nadir was severe, the outcome at 1 year was favorable for all seven patients even in the absence of specific treatment; in comparison, patients with $C$. jejuniassociated GBS in this region have a poor outcome [3]. The presence of anti-VZV IgM antibodies and absence of anti-GM1 and C. jejuni-related LOS antibodies in our seven patients - and absence of anti-VZV IgM antibodies and presence of anti-GM1 and C. jejuni-related LOS antibodies in patients with non-VZV-associated GBS - provides strong evidence of an etiological role for VZV in GBS. The systematic review revealed most other reported cases of GBS after VZV infection also had the sensory-motor type at clinical presentation (>50\%) and neurophysiological evidence of demyelination [13-42] (see Supplementary Tables 1 and 2). Bulbar cranial nerve involvement, mechanical ventilation, and residual disabilities appear more frequent among our Bangladeshi patients than the previously reported cases, possibly as none of our patients received specific immunotherapy, e.g., intravenous immunoglobulin or plasma exchange.

Varicella and shingles are the two clinical presentations of VZV infection. Primary VZV infection (varicella or chicken pox) typically presents with characteristic successive crops of widespread maculo-vesiculo-pustular skin eruptions associated with fever. Reactivation of dormant VZV infection, known as herpes zoster or shingles, characteristically presents with a similar skin rash confined unilaterally to a specified dermatomal area. Among patients with GBS, both presentations of VZV were predominantly associated with AIDP, the demyelinating form.

In contrast to AMAN, the pathogenesis of AIDP is largely unknown. Most patients with AMAN have preceding C. jejuni infections. Carbohydrate mimicry between C. jejuni LOS and peripheral nerve gangliosides triggers production of cross-reactive, neurotoxic, anti-ganglioside antibodies (e.g., GM1, GD1a, and GQ1b) [47]. In contrast, patients with AIDP rarely have a preceding $C$. jejuni infection or ganglioside antibodies. AIDP may be mediated by cytotoxic $\mathrm{T}$ cells, since extensive lymphocyte infiltration into the myelin sheath was observed during autopsies of three patients with AIDP [48], compared to a paucity of lymphocytic infiltration in the axonal subtype [49]. The $\mathrm{CD}^{+} \mathrm{T}$ cell subpopulation also differs in patients with AIDP compared to the axonal subtype [50]. The role of $\mathrm{T}$ cells in the pathogenesis of both AIDP and VZV infection is especially intriguing given the association between the demyelinating form of GBS and VZV. VZV is known to preferentially infect $\mathrm{CD} 4^{+}$memory $\mathrm{T}$ cells (with specific tissue-homing characteristics) in the lymphoid tissues of the upper respiratory tract, then $\mathrm{T}$ cells transport the virus to the tissues that are ultimately infected [51]. Current evidence suggests VZV actively remodels $\mathrm{T}$ cells into activated specific tissue-homing infected $\mathrm{T}$ cells. During the remodeling process, VZV induces a spectrum of changes in the surface and intracellular proteins within heterogeneous CD4 and CD8 T cell populations [52]. However, whether this leads to autoimmunity against nerves has yet to be determined. In addition, VZV can directly infect the peripheral nerves, which may produce the neurophysiologic features of peripheral nerve demyelination [53]. However, polyradiculoneuritis due to infection of nerve roots and/or nerves by VZV is unlikely, since weakness did not coincide with the skin rash in any case and none of the patients had an increased CSF cell count. Immune-mediated demyelination is also possible in other acute and mono or polyphasic neurological disorders preceded by VZV infection, including acute disseminated encephalomyelitis [54], acute transvers myelitis (ATM) [55], or the relapse phase of multiple sclerosis [56], suggesting VZV has immune-mediated demyelinating potential. In addition to a propensity for neuronal tissue, VZV may also potentially trigger giant cell arteritis (GCA), a form of autoimmune vasculopathy [57], with the pathophysiology further indicating VZV-mediated macrophase and $T$ cell-mediated inflammation.

In terms of exploring the pathogenic role of VZV in GBS, our study has several limitations. First, we did not perform PCR for VZV in CSF or serum and hence cannot completely exclude direct infection of the nerves by VZV. Second, we did not carry out complete screening of infectious etiologies that may trigger GBS (apart from VZV and C. jejuni), and third, we did not perform lymphocyte subset assays to further explore the role of cell-mediated immune mechanisms in the pathogenesis of GBS.

In conclusion, this study demonstrates VZV is associated with the demyelinating form of GBS, distinct to the $C$. jejunirelated axonal variants that predominate in Bangladesh. Further studies are required to explore the mechanisms by which VZV infection leads to damage to peripheral nerve myelin. 
Acknowledgments The icddr,b acknowledges the Government of Bangladesh's commitment, as well Global Affairs Canada (GAC), Swedish International Development Cooperation Agency (Sida), and UK Department for International Development (DFID). We are grateful to laboratory personnel at the Enteric Microbiology Laboratory Sciences \& Services Division (LSSD) and library personnel from icddr,b for their support. We are indebted to the neurologists who referred their patients to us.

Funding This research activity was funded by the icddr,b and the Government of Bangladesh.

\section{Compliance with ethical standards}

Conflict of interest No authors have any financial, professional, or personal conflicts of interest that may influence this manuscript to disclose.

\section{References}

1. Jacobs BC, Rothbarth PH, van der Meche FG, Herbrink P, Schmitz PI, de Klerk MA, van Doorn PA (1998) The spectrum of antecedent infections in Guillain-Barre syndrome: a case-control study. Neurology 51(4):1110-1115

2. Islam MB, Islam Z, Farzana KS, Sarker SK, Endtz HP, Mohammad QD, Jacobs BC (2016) Guillain-Barre syndrome in Bangladesh: validation of Brighton criteria. J Peripher Nerv Syst: JPNS 21(4): 345-351

3. Islam Z, Jacobs BC, van Belkum A, Mohammad QD, Islam MB, Herbrink P, Diorditsa S, Luby SP, Talukder KA, Endtz HP (2010) Axonal variant of Guillain-Barre syndrome associated with Campylobacter infection in Bangladesh. Neurology 74(7):581-587

4. Orlikowski D, Porcher R, Sivadon-Tardy V, Quincampoix JC, Raphael JC, Durand MC, Sharshar T, Roussi J, Caudie C, Annane D et al (2011) Guillain-Barre syndrome following primary cytomegalovirus infection: a prospective cohort study. Clin Infect Dis: Off Publ Infect Dis Soc Am 52(7):837-844

5. Mori M, Kuwabara S, Miyake M, Noda M, Kuroki H, Kanno H, Ogawara K, Hattori T (2000) Haemophilus influenzae infection and Guillain-Barre syndrome. Brain J Neurol 123(Pt 10):2171-2178

6. Cao-Lormeau VM, Blake A, Mons S, Lastere S, Roche C, Vanhomwegen J, Dub T, Baudouin L, Teissier A, Larre P et al (2016) Guillain-Barre syndrome outbreak associated with Zika virus infection in French Polynesia: a case-control study. Lancet (Lond, Engl) 387(10027):1531-1539

7. Hadden RD, Cornblath DR, Hughes RA, Zielasek J, Hartung HP, Toyka KV, Swan AV (1998) Electrophysiological classification of Guillain-Barre syndrome: clinical associations and outcome. Plasma Exchange/Sandoglobulin Guillain-Barre Syndrome Trial Group. Ann Neurol 44(5):780-788

8. Ho TW, Mishu B, Li CY, Gao CY, Cornblath DR, Griffin JW, Asbury AK, Blaser MJ, McKhann GM (1995) Guillain-Barre syndrome in northern China. Relationship to Campylobacter jejuni infection and anti-glycolipid antibodies. Brain J Neurol 118(Pt 3): 597-605

9. Hiraga A, Mori M, Ogawara K, Kojima S, Kanesaka T, Misawa S, Hattori T, Kuwabara S (2005) Recovery patterns and long term prognosis for axonal Guillain-Barre syndrome. J Neurol Neurosurg Psychiatry 76(5):719-722

10. van Doorn PA, Ruts L, Jacobs BC (2008) Clinical features, pathogenesis, and treatment of Guillain-Barre syndrome. Lancet Neurol 7(10):939-950

11. Hughes RA, Cornblath DR (2005) Guillain-Barre syndrome. Lancet (Lond, Engl) 366(9497):1653-1666
12. Kang JH, Sheu JJ, Lin HC (2010) Increased risk of Guillain-Barre syndrome following recent herpes zoster: a population-based study across Taiwan. Clin Infect Dis: Off Publ Infect Dis Soc Am 51(5): 525-530

13. Tatarelli P, Garnero M, Del Bono V, Camera M, Schenone A, Grandis M, Benedetti L, Viscoli C (2016) Guillain-Barre syndrome following chickenpox: a case series. Int J Neurosci 126(5):478-479

14. Cokyaman T, Karli A, Tekin E, Sensoy G, Tasdemir HA (2015) An uncommon association: chicken pox and Guillain-Barre syndrome. J Infect Public Health 8(2):216-217

15. Buonsenso D, Focarelli B, Valentini P, Onesimo R (2012) IVIG treatment for VZV-related acute inflammatory polyneuropathy in a child. BMJ Case Rep, 2012

16. Munoz-Sellart M, Garcia-Vidal C, Martinez-Yelamos S, Niubo J, Fernandez-Viladrich P (2010) Peripheral facial palsy after varicella. Report of two cases and review of the literature. Enferm Infecc Microbiol Clin 28(8):504-508

17. Modi M, Singla M, Aggarwal N, Singla V, Sharma A (2010) Guillain-Barre syndrome in pregnancy: a rare complication of varicella. Taiwan J Obstet Gynecol 49(3):364-365

18. Cresswell F, Eadie J, Longley N, Macallan D (2010) Severe Guillain-Barré syndrome following primary infection with varicella zoster virus in an adult. Int J Infect Dis 14(2):e161-e163

19. Juntas Morales R, Tillier JN, Davous P (2009) Facial diplegia and acute inflammatory demyelinating neuropathy secondary to varicella. Rev Neurol 165(10):836-838

20. Girija AS, Rafeeque M, Abdurehman KP (2007) Neurological complications of chickenpox. Ann Indian Acad Neurol 10(4): 240-246

21. Hamad AI, Ghadban WK, Hamad AA, Al-Hail HJ (2002) Postvaricella Guillain Barre syndrome. Neurosciences (Riyadh, Saudi Arabia) 7(4):299-300

22. Chua HC, Tjia H, Sitoh YY (2001) Concurrent myelitis and Guillain-Barre syndrome after varicella infection. Int J Clin Pract 55(9):643-644

23. Barriga FJ, Martin M, Castilla V, Dobato JL, Pareja JA, Vela L (2000) Severe Guillain-Barre syndrome following initial infection with varicella in a young adult. Rev Neurol 31(3):297-300

24. Yoshikawa T, Suzuki K, Suga S, Miyata E, Yamamoto H, Hosokawa T, Kumagai T, Asano Y (2000) Immune response to gangliosides in a case of Guillain-Barre syndrome after varicella. Arch Dis Child 83(2):172-173

25. Padilla F, Chamorro MI, Heras-Perez JA, Romero-Acebal M (1998) Guillain-Barre and varicella infection. Rev Neurol 26(154):1075-1076

26. Fabienne Picard CAG, Frey M, Collard M (1997) Varicella with acute motor axonal neuropathy. Eur Neurol 38(1):68-71

27. Sabogal CE (1997) Index of suspicion. Case 2. Guillain-Barre syndrome. Pediatr Rev / Am Acad Pediatr 18(10):357-359

28. da Rosa-Santos OL, Moreira AM, Golfetto CA, Maceira JP, Ramos-e-Silva M (1996) Guillain-Barré syndrome associated with varicella-zoster infection. Int J Dermatol 35(8):603-604

29. Ormerod IE, Cockerell OC (1993) Guillain-Barre syndrome after herpes zoster infection: a report of 2 cases. Eur Neurol 33(2):156 158

30. Sanders EA, Peters AC, Gratana JW, Hughes RA (1987) GuillainBarré syndrome after varicella-zoster infection. Report of two cases. J Neurol 234(6):437-439

31. Murthy JM (1987) Acute inflammatory demyelinating polyradiculoneuropathy following varicella. Postgrad Med J 63(745):977-978

32. Velin P, Dupont D, Gasiglia ML (1987) Guillain-Barre syndrome and chickenpox, a case. Pediatrie 42(6):445-446

33. Neki NS, Tamilmani IS, Gupta H (2013) Gullian-Barre syndrome associated with herpes zoster virus infection - a case report. JIMSA 26(2) 
34. Nagane Y, Utsugisawa K, Obara D (2006) A case of herpes zoster associated Guillain-Barré syndrome with a relapse of eruptions after intravenous immunoglobulin therapy. Clin Neurol 46(9):664-667

35. Wakasugi K, Imaizumi T, Nishimura Y, Fujimoto H, Ayabe M, Shoji H, Iijima H (2001) Guillain-Barre syndrome associated with herpes zoster. Intern Med (Tokyo, Japan) 40(6):552

36. Roccatagliata L, Uccelli A, Murialdo A (2001) Guillain-Barré syndrome after reactivation of varicella-zoster virus. N Engl J Med 344(1):65-66

37. Yamaguchi M, Chiba A, Yanagawa $\mathrm{T}$, Mato $\mathrm{T}$, Hirai $\mathrm{K}$, Inoue $\mathrm{T}$, Oya Y, Kusunoki S, Ito K, Yamamoto K (2001) Guillain-Barré syndrome following herpes zoster in a patient with systemic sclerosis. Mod Rheumatol 11(3):251-254

38. Barkat A, Fazal EET, Turett GS (1995) Guillain Barre syndrome following herpes zoster in an HIV-1 infected patient. Infect Dis Clin Pract 4(4):314-315

39. Rabbani MU, Gupta D (1990) Guillain Barre syndrome following herpes zoster: a case report and review of literature. Jpn J Med 29(4):397-398

40. Hart IK, Kennedy PG (1987) Guillain-Barre syndrome associated with herpes zoster. Postgrad Med J 63(746):1087-1088

41. Dayan AD, Ogul E, Graveson GS (1972) Polyneuritis and herpes zoster. J Neurol Neurosurg Psychiatry 35(2):170-175

42. Knox JD, Levy R, Simpson JA (1961) Herpes zoster and the Landry-Guillain-Barre syndrome. J Neurol Neurosurg Psychiatry $24: 167-172$

43. Asbury AK, Cornblath DR (1990) Assessment of current diagnostic criteria for Guillain-Barre syndrome. Ann Neurol 27(Suppl):S21-S24

44. Ang CW, Krogfelt K, Herbrink P, Keijser J, van Pelt W, Dalby T, Kuijf M, Jacobs BC, Bergman MP, Schiellerup P et al (2007) Validation of an ELISA for the diagnosis of recent Campylobacter infections in Guillain-Barre and reactive arthritis patients. Clin Microbiol Infect: Off publ Eur Soc Clin Microbiol Infect Dis 13(9): 915-922

45. Kuijf ML, van Doorn PA, Tio-Gillen AP, Geleijns K, Ang CW, Hooijkaas H, Hop WC, Jacobs BC (2005) Diagnostic value of anti-GM1 ganglioside serology and validation of the INCATELISA. J Neurol Sci 239(1):37-44
46. Islam Z, Gilbert M, Mohammad QD, Klaij K, Li J, van Rijs W, TioGillen AP, Talukder KA, Willison HJ, van Belkum A et al (2012) Guillain-Barre syndrome-related Campylobacter jejuni in Bangladesh: ganglioside mimicry and cross-reactive antibodies. PLoS One 7(8):e43976

47. Willison HJ, Jacobs BC, van Doorn PA (2016) Guillain-Barre syndrome. Lancet (Lond, Engl) 388(10045):717-727

48. Griffin JW, Li CY, Ho TW, Xue P, Macko C, Gao CY, Yang C, Tian M, Mishu B, Cornblath DR (1995) Guillain-Barre syndrome in northern China. The spectrum of neuropathological changes in clinically defined cases. Brain J Neurol 118(Pt 3):577-595

49. Griffin JW, Li CY, Ho TW, Tian M, Gao CY, Xue P, Mishu B, Cornblath DR, Macko C, McKhann GM et al (1996) Pathology of the motor-sensory axonal Guillain-Barre syndrome. Ann Neurol 39(1):17-28

50. Hou HQ, Miao J, Feng XD, Han M, Song XJ, Guo L (2014) Changes in lymphocyte subsets in patients with Guillain-Barre syndrome treated with immunoglobulin. BMC Neurol 14:202

51. Zerboni L, Sen N, Oliver SL, Arvin AM (2014) Molecular mechanisms of varicella zoster virus pathogenesis. Nat Rev Microbiol 12(3):197-210

52. Sen N, Arvin AM (2016) Dissecting the molecular mechanisms of the tropism of varicella-zoster virus for human T cells. J Virol 90(7): 3284-3287

53. Cortese A, Tavazzi E, Delbue S, Alfonsi E, Pichiecchio A, Ceroni M, Ferrante P, Marchioni E (2009) Varicella zoster virus-associated polyradiculoneuritis. Neurology 73(16):1334-1335

54. Berth S, Carbunar O, Yang NS, Fredericks B, Lipton HL, ValyiNagy T (2015) Varicella-zoster virus encephalomyelitis with a prominent demyelinating component. Neuropathology 35(6):587-591

55. Devinsky O, Cho ES, Petito CK, Price RW (1991) Herpes zoster myelitis. Brain J Neurol 114(Pt 3):1181-1196

56. Sotelo J, Ordonez G, Pineda B, Flores J (2014) The participation of varicella zoster virus in relapses of multiple sclerosis. Clin Neurol Neurosurg 119:44-48

57. Gilden D, Nagel MA (2016) Varicella zoster virus triggers the immunopathology of giant cell arteritis. Curr Opin Rheumatol 28(4): 376-382 